\title{
Innovative elektrische Flugzeugkabinennetze für eine optimierte Bordnetzversorgung
}

Demonstrator moderne elektrische Kabinenarchitektur

In diesem Teilprojekt werden innovative Architekturkonzepte zur Technologiereife entwickelt. Dabei werden unterschiedliche elektrische Bordnetzarchitekturen anhand konventioneller Flugzeugkabinennetze untersucht. Die Abbildung zeigt den schematischen Aufbau im Kabinen- und Frachtbereich eines traditionellen Bordenetzes (links) und eines Architekturkonzeptes mit höherer Gleichspannung (HVDC) (rechts).
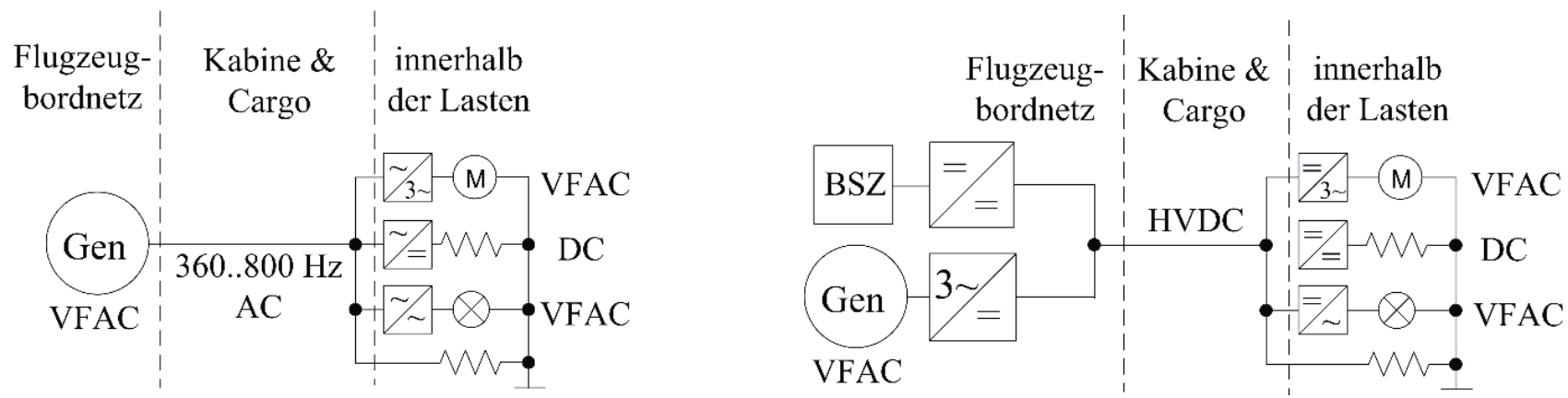

Ein Forschungsschwerpunkt stellt die Gewichtsoptimierung der Verkabelung in der Kabine sowie im Frachtraum dar. Darüber hinaus werden Szenarien im Zusammenhang mit der Einführung von Faserverbundstoffen (CFK) und Hybrid-Werkstoffen analysiert.

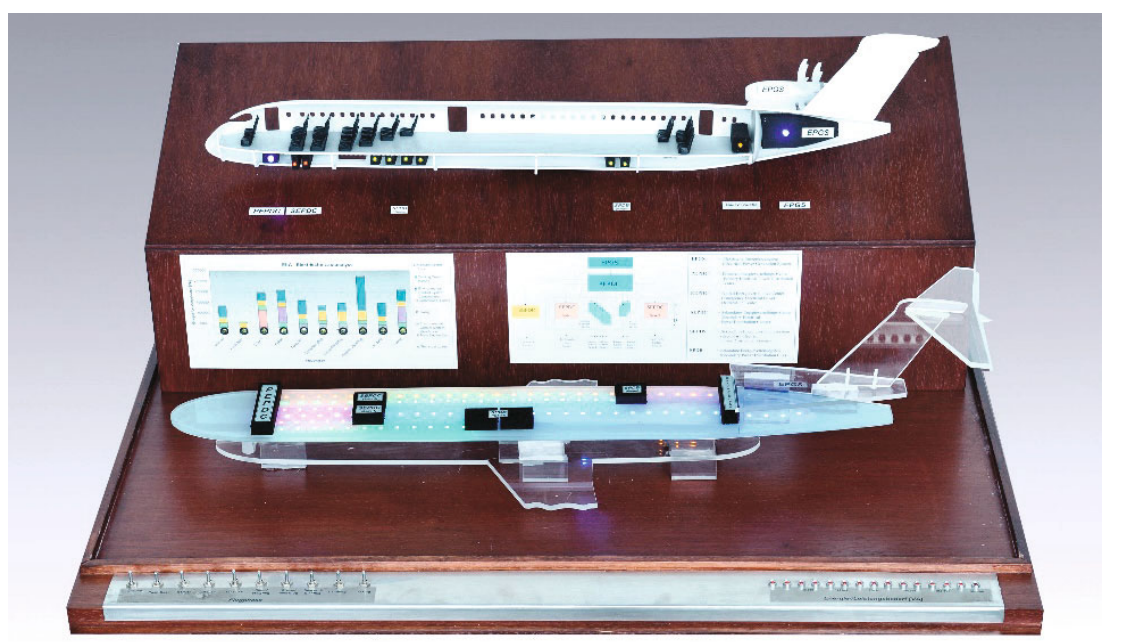

Der Demonstrator zeigt ein optimiertes Flugzeugkabinennetz eines Mittelstreckenflugzeugs sowie die Leistungsanforderung der einzelnen Flugphasen zwischen Start und Ziel der Reiseroute. Die Hauptverteilung des Energiever-sorgungsnetzes ist im PEPDC (Primary Power Distribution Center) gebündelt. Über PowerFeeder werden Unterverteiler (SPDBs - Secondary Power Distribution Boxes) mit Spannung versorgt. Die Lasten wiederum sind an den Unterverteilern angeschlossen und werden dort abgesichert. Dabei ergeben sich folgende Optimierungsansätze:

- Finden einer gewichtsoptimierten Verteilerstruktur

- Erhöhung der Versorgungsspannung

- Optimale Positionierung der Unterverteiler im Flugzeug

- Einsatz von gewichtsoptimierten Kabelbündeln

- Gewichtsoptimierte Verteilung des erlaubten Spannungsabfalls auf Power- und Lastverkabelung

- Schutzkleinspannungskonvertierung innerhalb der SPDB 